\title{
UNATTENDED GROUND SENSOR BORDERS - THE FORGOTTEN SOLUTION FOR AFGHANISTAN
}

\author{
Laviniu BOJOR, Ionut Alin CÎRDEI \\ "Nicolae Bălcescu" Land Forces Academy, Sibiu, Romania \\ laviniu.bojor@gmail.com, cirdei_alin@yahoo.com
}

\begin{abstract}
Recent military conflicts identify the permanent feature of weaker combatants to take refuge in sanctuaries outside areas of responsibility. These territories in the vicinity of theaters of operations were used mainly for protection and survival but also for the recruitment, equipment, training or supply and support of forces directly involved in military actions. The expansion of the Hon Chi Min Trail supply network through Laos and Cambodia or the installation of a Taliban safe haven in Pakistan are examples that confirm their impact on the end result. The paper aims to analyze strategies that use sensors, drones and other capabilities specific to today's arsenal of technology that can support military leaders in the field in solving this challenge of monitoring and controlling the boundaries of a theater of operations (TO).
\end{abstract}

\section{Keywords: safe haven, Afghan war, Hon Chi Min Trail, the Morice Line}

\section{Introduction}

Afghanistan was not the only case in which technological supremacy failed to be sufficient to win the war. The US military was forced to withdraw from its first modern conflict - "Vietnam War", without reaching the proposed goals, although the statistics developed by the innovative Planning, Programming, Budgeting System (PPBS) [1] showed favorable body counts and kill ratios. The Vietnam War identified the problem of troop mobility and developed air transport capabilities through the use of high-tech means: the helicopters and other technological equipment and systems available at the time: fighter jets, armored vehicles, conventional and nuclear-powered aircraft carriers, automatic weapons, anti-tank missiles, directional anti-personnel mines, sensors or even computers. They won the military battles but lost the war as a whole because they fought against an opponent who was much weaker technologically but fiercely loyal to their leadership and devoted to communist ideology.

Many analysts explained the loss of war as a result of the jungle and the vegetation in the field that allowed the enemy to find shelter from the destructive force of the American arsenal. The relief was not the main cause, but it gave the opponent great mobility and the opportunity to be supplied with the help of the Hon Chi Min Trail. The external support provided by Russia and China (\$ 2 billion) [2], combined with winning the "hearts and minds" of the locals, the volunteering actions of the population in the North, or the corruption of the Government of the South ultimately led to a result hard to be understood.

Half a century later, in 2014, the powerful NATO-led International Security Assistance Force (ISAF) Coalition was forced to withdraw most of its troops from Afghanistan without waving a clear victory. The Taliban leader, Osama Bin Laden, was killed in Pakistan but the Afghan 
insurgency had long adapted its force structures to small, independent cells, capable of continuing the fight even if they had lost an important leader. As in Vietnam, ISAF forces failed both to secure the border with Pakistan (which allowed the supply of insurgents and withdrawal to "safe haven") and to gain popular support.

\section{Isolating the borders - a key point of military conflicts}

As we have mentioned before, most of the previous conflicts were marked by the external support of some proxy states. The first vulnerability that future military leaders can solve with the help of technology and artificial intelligence (AI) equipment is the control of TO borders. Continuous supply through the Hon Chi Min Trail in the Vietnam War, the lack of border control at the border with Syria and Iran in the Iraq War, or Taliban access to "safe haven" in Pakistan proved that we must deprive our opponent of any possible external support and make it impossible for them to withdraw to a sanctuary located outside their legitimate mandate. Pakistan's double game was not initially known, and not even the fact that there was not any human resource that could block the 2430 $\mathrm{km}$ of common border. This vulnerability was one of the causes that led to no positive results. If the map of Afghanistan is analyzed, we can easily notice that International Security Assistance Force (ISAF) should have also blocked the western side of the country because Iran is not a NATO friendly state either. Isolation by building a physical wall made of barbed wire or concrete, like in Israel, is not a real option if the costs involved are considered, but it is very effective if it looks at the results achieved by the Israeli Defense Forces (IDF) effort to stop the terrorist attacks coming from Egypt, Lebanon, Gaza Strip and West Bank [3].

\section{The Morice Line - the effective solution of the Algerian war}

The construction of a physical wall was an effective method in the Algerian conflict
(1954-1962), when the freshly defeated French military forces in Vietnam, at Dien Bien Phu, felt helpless again in front of the rebel forces that were exploiting the advantage of the sanctuaries offered by neighboring countries like Tunisia or Morocco. The solution found was the construction of "the Morice Line", a physical barbed wire wall, electrified and doubled by mine fields, much easier to be controlled by the French.

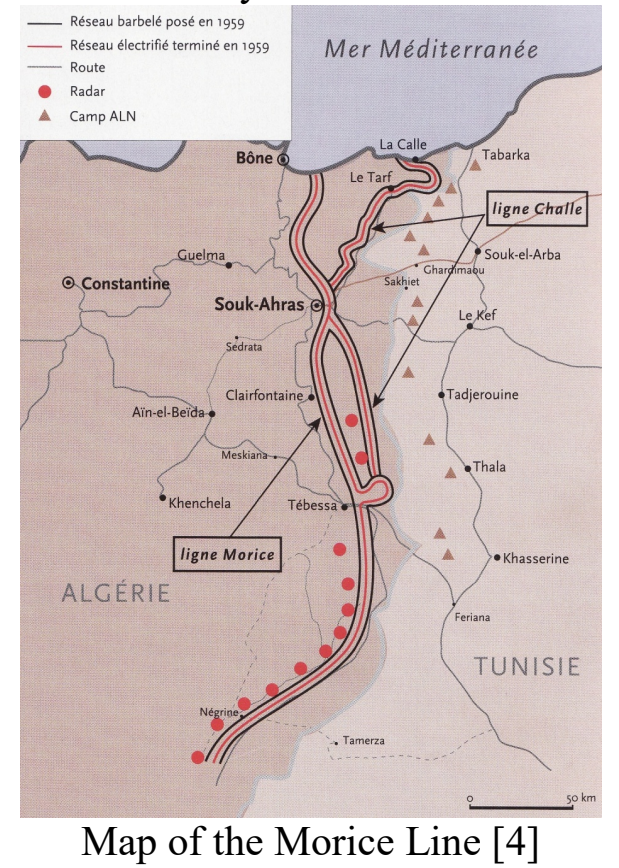

The efforts of the Front de Liberation Nationale (FLN), isolated in Tunisia, to break "the Morice Line" included all the methods available at that time, such as using high voltage wire cutters, hooks to lift up the wire, digging under the wire, climbing the fence with insulated materials or using explosive loads. Diversions were also created by small groups and their purpose was to distract the attention of the French military forces while larger groups were trying to cross the border in other places. There were also used bypass routes, crossing the Sahara desert, or even frontal attack on vulnerable parts of the wall. When the wall was attacked, the alarm activated the closest ground forces that initiated fire from $105 \mathrm{~mm}$ howitzers or rapid reaction with helicopters, tanks and airborne infantry. The wall built by the French led to 
denying external support and reduced the infiltration of FLN forces by $90 \%$. The guerrilla fighters that were isolated inside Algeria and that left without weapons and ammunition became an "easy prey" for the French army who managed, with the help of the Morice line, to change the outcome of the seemingly lost conflict [5]. Finally, Algeria gained its independence (1962), but "The Morice line", a miracle of technology at the time, is the best example of the fact that isolating the theater of operations is a necessity. The Morice Line of Alger, along with other previous examples such as the Hadrian's Wall of the Roman Empire, the Great Wall of China or even the Maginot Line in France, confirmed the advantage of some defensive military constructions.

\section{Operation Igloo White - Vietnam War}

The analysis of the physical terrain in Vietnam highlighted the impossibility of erecting a wire wall, similar to that in Algeria, to stop traffic from the north. A group of scientists known as the Jasons, founded by ARPA (now DARPA), suggested a virtual wall, a network of sensors to detect the routes of resupply, reinforcement and replacement of combat casualties built by using the camouflage provided by forested areas as a cover. It represented the "integration of a large- scale network of sensors and navigation systems to detect and locate the movement of enemy forces under cover or at night, linked with means of engaging the enemy forces immediately once the sensor network has provided their locations and directions of movement" [6]. About 20,000 sensors were used in Vietnam, most of them planted in the air. Acoustic, seismic, or even "people sniffer" (chemical) sensors were thrown at night to capture the noisy sounds of diesel trucks, the clatter of bicycles used by convoys on foot or even the sweat and human urine [7]. Signals identified on the ground were captured by aircraft orbiting over the area and were transmitted to the Infiltration Surveillance Center at Nakhon Phanom Air Base in Thailand [8]. This command center analyzed the accuracy of the signals and filtered any false alarms generated by rain, wind or animals. The positive identification of human presence in these areas used by the North Vietnamese People's Army of Vietnam (PAVN) was followed by the activation of means to hit targets, which, in the specific case of the inaccessible land in Vietnam and the localization of the route in Laos or Cambodia, materialized mainly in air strikes or artillery fire as shown in Figure 1.

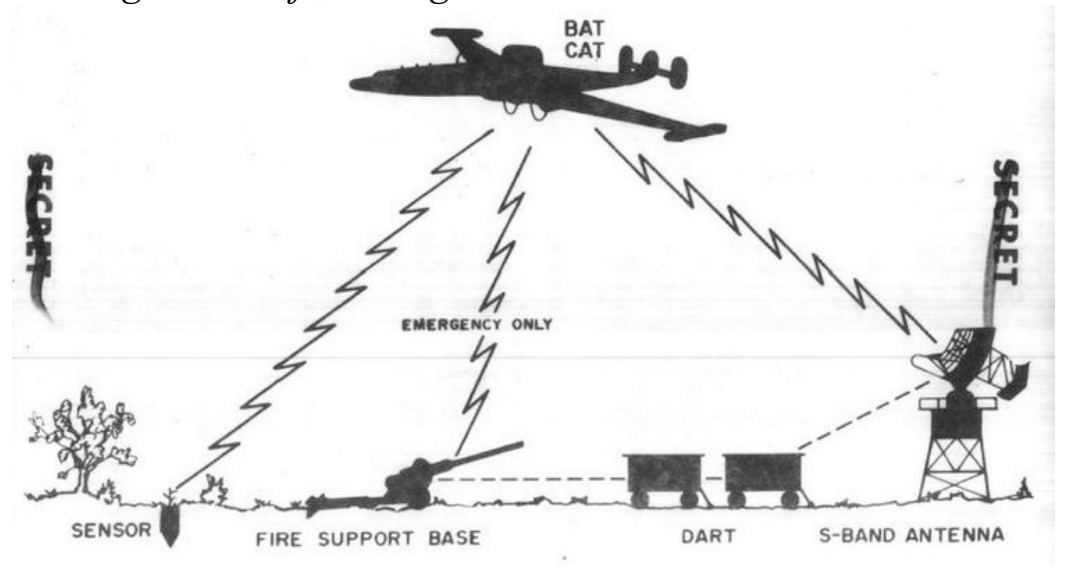

Figure 1: The design of Igloo White operation [9]

This initially secret approach, the "sensor to shooter" link, known by various names such as "Igloo White", "Air Supported Anti-Infiltration Barrier", "Electronic
Battlefield" or "McNamara Line", was an innovative method at that time but it was not treated the same as the French did in Algeria. 
The design of the system was well planned but it was not respected as it was intended by the Jasons because no air means were specifically allocated for immediate intervention at the locations signaled by the sensors. The reaction was carried out only with the available air means and, often, these were not available or even insufficient. The aerial intervention could not be duplicated by the terrestrial one, so it was not possible to prove that the signals received from the sensors were real and that the bombardments reached their target. A real evaluation of the system's functioning could not be carried out, and the reserves continued to reach the South. So it was not possible to justify the huge budget spent for the permanent replacement of the sensors running out of battery or the allocation of military resources that were indispensable in other hot places in Vietnam.

Also, PAVN, once they identified the role of semi-buried or hanging in trees devices, tried to intentionally deceive the intentional "spoofing" of the network. They sent animals on alternate routes or even left "buckets of urine near sensors in nonessential areas. When the sensors detected a large group's worth of urine, US airstrikes would begin heavily bombing no one in particular" [10].

Even if there had been air means especially designed for intervention on the signaled areas, it could not be estimated that the system would have been able to stop the infiltration of the PAVN, who were highly motivated to find alternative supply routes. The vastness of the forested area and the technological impossibility of the $70 \mathrm{~s}$ to create a persistent surveillance wall, along the entire length of the borders in Vietnam, confirm that it was an objective too daring for those times.

Eventually, the system was stopped although it had reached the stage when the algorithms that were analyzing the data in Thailand command center were hard to fool: "targets were distinguished from false alarms caused by animals, aircraft overflights, and even heavy rainfall, through the use of computer algorithms implemented on two advanced IBM-360 computers (later reduced to one)" [10]. Moreover, the technological progress of the moment, although insufficient to reach the set objectives, allowed even recording the conversations between North-Vietnamese soldiers situated near the American sensors: " a North Vietnamese NCO is heard telling a trooper to climb a tree to get the parachute from an Acoubuoy snagged in the foliage. He wanted to give the material to his girlfriend to make a dress" [11].

Even though it was blamed by some because of the necessary resources and lack of real reports, although we do not currently have access to data from the Vietnam archives to confirm whether or not it was an effective system, the application of this sensor network saved the US military from a defeat similar to that suffered by the French at Dien Bien Phu. The assault on the US base at Khe Sanh, which remained isolated for more than 70 days, would certainly have had another outcome if it had not benefitted from the information received through the sensors planted around the base.

\section{Conclusions}

Unfortunately, after the failure in Vietnam, subsequent military doctrines did not focus on isolating theaters of operations. The following question arises: why the postconflict military doctrine in Vietnam, the US or NATO, while identifying the importance of these systems, did not put more emphasis on the implementation of these Unattended Ground Sensor borders in subsequent conflicts such as Afghanistan? The technological breakthrough reached a maturity that allows it to overcome the problem of short life batteries of the sensors in Vietnam and any false alarms can be verified by analysis of imagery and geospatial information. Loading the data collected by sensors in AI machines and developing algorithms capable of learning the difference between moving tribes from the Afghan border and infiltrating the 
Talibans from Pakistan safe-havens could be the winning solution of the International Security Assistance Force (ISAF). And the terrain of Afghanistan, unlike that of Vietnam, allowed building physical walls that could direct the flow to certain controllable transport routes, at the same time with the electronic surveillance of the impracticable areas, transformed in "no man's land".

The interpretation of comprehensive GEOINT products, obtained using satellite, airborne, ground-based and sea-based platforms equipped with electro-optical (EO) and radar sensors, should be in the attention of all military leaders in the theaters of operations. These data, once introduced in AI learning machines, are capable of distinguishing the anomalies of terrorist groups from locals' patterns of life and offer effective solutions to prohibit the adversary's refuge to outside sanctuaries or the support offered by other proxy states.

Building a physical wall was an impossible mission for TO Afghanistan because we are talking about a country with large territorial areas surrounded by more or less friendly NATO neighbors. But the issue of a Taliban safe haven on the border with Pakistan could be addressed by creating a virtual wall, an automatic monitoring network to signal the opponent's intention to infiltrate or provide support to the antigovernment forces inside. This strategy could be the solution that turned failure into victory.

The evolution of AI and internet of things (IoT) devices force us to analyze the technological solutions belonging both to military and civilian environments that can help military leaders in the missions they will receive during future military conflicts. These virtual monitoring networks must be based on artificial intelligence that can be used at full capacity to find effective solutions for surveillance, alerting and control of territorial borders in order to forbid the opponent's refuge to the safe haven and also block the support provided from other proxy states to forces that remained trapped inside.

\section{References List}

[1] Don Vito, P. A., The Essentials of a Planning-Programming-Budgeting System. Santa Monica, CA: RAND Corporation, 1969. Available from: https://www.rand.org/pubs/papers/P4124.html.

[2] https://www.bbc.co.uk/bitesize/guides/z342mp3/revision/4.

[3] Miriam Valverde, "Border fence in Israel cut illegal immigration by 99 percent", February 13th, 2017, available from: on https://www.politifact.com/truth-ometer/statements/2017/feb/13/ron-johnson/border-fence-israel-cut-illegal-immigration-99per/.

[4] Available from: https://docplayer.fr/57391186-Pour-une-vive-memoire.html.

[5] Report: "Defeating Insurgency On The Border", available from: https://www.globalsecurity.org/military/library/report/1985/HJR.htm.

[6] Seymour J. Deitchman, The "Electronic Battlefield" in the Vietnam War, The Journal of Military History, Volume 72, Number 3, July 2008, p. 874, (Article) Published by Society for Military History, DOI: https://doi.org/10.1353/jmh.0.0024.

[7] Matt Novak, "How the Vietnam War Brought High-Tech Border Surveillance to America", available from https://paleofuture.gizmodo.com/how-the-vietnam-warbrought-high-tech-border-surveillan-1694647526.

[8] John T. Correll, "Igloo White", November 2004, accessed on 25.01.2021 http://www.airforcemag.com/MagazineArchive/Pages/2004/November\%202004/1104ig loo.aspx.

[9] https://alchetron.com/Operation-Igloo-White. 
[10] Matt Novak, "How the Vietnam War Brought High-Tech Border Surveillance to America", available from: https://paleofuture.gizmodo.com/how-the-vietnam-warbrought-high-tech-border-surveillan-1694647526.

[11] John T. Correll, "Igloo White", November 2004, available from: http://www.airforcemag.com/MagazineArchive/Pages/2004/November\%202004/1104ig loo.aspx. 